\title{
PENGARUH WAKTU PEMANASAN TERHADAP AKTIVITASANTIOKSIDANDAN DAYA TERIMA SELAI BUAH NAGA MERAH (Hylocereus polyrhizus)
}

\author{
Dyah Titin Laswati \\ ${ }^{1}$ Program Studi Teknologi Pangan, Fakultas Sains dan Teknologi (e-mail : dyah.dtl@gmail.com) \\ Universitas Widya Mataram Yogyakarta, nDalem Mangkubumen KT III. Ngasem Yogyakarta
}

\begin{abstract}
Red dragon fruit has high biocative compounds including betacyanin and anthocyanin which are the best antioxidants from the flavonoid class. This study aims to determine the antioxidant activity and panelist acceptance of red dragon fruit jam. The process of making red dragon fruit jam each treatment is by heating the red dragon fruit, each treatment is $500 \mathrm{~g}$ and heated to boiling over medium heat for 30 minutes, then added sugar $(200 \mathrm{~g})$ each treatment until boiling at different times each-each for 5 minutes, 10 minutes, 15 minutes, 20 minutes and 25 minutes temperature of $90-100^{\circ} \mathrm{C}$ or a total heating of 35 each; 40; 45; 50; and 55 minutes. The design of the experiment was RAL with 3 replications for each treatment. The parameters tested include water content, total sugar content, antioxidant activity and organoleptic properties are color, texture/thickness and preference. Organoleptic testing by Scoring different test and Hedonic scale test. The panelists used were 30 panelists. The results of the study included chemical analysis of the red dragon fruit jam successively. The following water content was 35.5\%; 34.29\%; $30.38 ; 26.73$; and $25.11 \%$. Antioxidant activity (\% RSA) as follows $60.57 ; 56.58 ; 54.51 ; 50.56$ and 50.19 . Total sugar levels as follows $49.32 \%$; $56.60 \% 58.37 \%$; 60.89; and 69.33\%. Organoleptic test results on red dragon fruit jam, panelists stated like score (4.6) against red dragon fruit jam by cooking 45 minutes with purplish red/pink score (3.45) and solid texture and clay score (3.9).
\end{abstract}

Keywords: heating time, red dragon fruit, jam

\begin{abstract}
ABSTRAK
Buah naga merah memiliki kandungan senyawa biokatif yang tinggi antara lain betasianin dan antosianin yang merupakan antioksidan terbaik dari kelas flavonoid. Penelitian ini bertujuan untuk mengetahui aktivitas antioksidan dan daya terima panelis terhadap selai buah naga merah. Proses pembuatan selai buah naga merah setiap perlakuan adalah memanaskan buah naga merah masing-masing perlakuan $500 \mathrm{~g}$ dan dipanaskan sampai mendidih dengan api sedang selama 30 menit kemudian ditambahkan gula pasir (200 g) tiap perlakuan sampai mendidih dengan waktu berbeda masing-masing selama 5 menit, 10 menit, 15 menit, 20 menit dan 25 menit suhu $90-100^{\circ} \mathrm{C}$ atau total pemanasan masingmasing 35; 40; 45; 50; dan 55 menit. Rancangan percobaan yang dilakukan adalah RAL dengan ulangan 3 kali untuk tiap perlakuan. Parameter yang diuji antara lain kadar air, kadar gula total, aktivitas antioksidan dan sifat organoleptik adalah warna, tekstur/kekentalan dan kesukaan. Pengujian organoleptik secara Scoring different test dan Hedonic scale test. Panelis yang digunakan 30 panelis.Hasil penelitian meliputi analisis kimia pada selai buah naga merah berturut-turut Kadar air sebagai berikut $35,5 \% ; 34,29 \% ; 30,38 ; 26,73$; dan 25,11\%. Aktivitas antioksidan (\%RSA) sebagai berikut 60,57; 56,58; 54,51; 50,56 dan 50,19. Kadar gula total sebagai berikut 49,32\%; 56,60\%; 58,37\%; 60,89; dan 69,33\%. Hasil uji organoleptik terhadap Selai buah naga merah, panelis menyatakan suka skor $(4,6)$ terhadap selai buah naga merah dengan pemasakan 45 menit dengan warna merah keunguan/pink skor $(3,45)$ dan tekstur kompak dan liat skor $(3,9)$.
\end{abstract}

Kata kunci: waktu pemanasan, buah naga merah, selai 


\section{PENDAHULUAN}

Selai atau jam (bahasa Inggris) atau confiture (bahasa Perancis) merupakan salah satu jenis makanan awetan berupa sari buah atau buah-buahan yang sudah dihancurkan, ditambah gula dan dimasak hingga kental atau berbentuk setengah padat.Buah naga merah memiliki kandungan senyawa biokatif yang tinggi. Dalam kehidupan sehari-hari kita tidak dapat terbebas dari senyawa radikal bebas. Asap rokok, makanan yang digoreng, asap kendaraan bermotor dan lain-lain merupakan beberapa sumber pembentuk radikal bebas. Radikal bebas merupakan molekul yang memiliki satu atau lebih elektron yang tidak berpasangan yang menyebabkan sifatnya sangat reaktif terhadap sel-sel penyusun jaringan tubuh dengan cara mengikat elektron sel-sel tubuh (Pietta, 1999; Andarwulan, dkk., 1996). Reaksi ini disebut sebagai peristiwa oksidasi yang bersifat merusak sel maupun jaringan.Antioksidan dapat menangkap radikal bebas dan mendetoksifikasinya (Kumaran dan Karunakaran, 2005). Antioksidan sintetik, seperti ter-butil hidroksitoluen (BHT) dan terbutil hidroksianisol (BHA), tersedia secara komersial, dan saat ini digunakan dalam proses industri. Namun, karena diduga sebagai promotor efek samping karsinogenesis dan efek negatif lainnya, maka penggunaan antioksidan sintetik dalam makanan, produk kosmetik, dan sediaan farmasi telah menurun. Antosianin diyakini mempunyai efek antioksidan yang sangat baik. Sebuah penelitian yang dilakukan di Universitas Michigan Amerika menunjukkan bahwa antosianin dapat menghancurkan radikal bebas, lebih efektif daripada vitamin E yang selama ini telah dikenal sebagai antioksidan kuat (Winarno,1997). Penelitian lain di Amerika Serikat membuktikan bahwa antosianin merupakan antioksidan paling kuat diantara kelas flavonoid lainnya. Kandungan antosianin diyakini dapat menghambat berbagai radikal bebas eperti radikal superoksida dan hidrogen peroksida. Antosianin dan berbagai bentuk turunannya dapat menghambat berbagai reaksi oksidasi dengan berbagai mekanisme (Astawan dan Kasih., 2008).Tanaman lain yang dapat dimanfaatkan sebagai sumber antioksidan alami salah satunya adalah Kedondong hutan (Spondias pinnata (1.f) kurz), Mengkudu (Morinda citrifolia) dan Kelor (Moringa oleifera) Ketiga tanaman tersebut banyak dimanfaatkan oleh masyarakat sebagai obat tradisional dan mempunyai potensi sebagai antioksidan (Pitojo dan Sumiati, 2005).

Penelitianinibertujuanuntukmengetahu i perubahan kimia dan organoleptik selai buah naga merah yang dipanaskan dengan berbagai lama waktu yang berbeda-beda.
1. Menentukankondisi waktu optimumpada pemasakan selai buah naga merah

2. Mengetahuikarakteristikkimia (antioksidan, kadar gula total, kadar air)dansifat organoleptik (warna, tekstur dan kesukaan secara keseluruhan)

\section{BAHAN DAN METODE}

Bahan penelitian adalah Buah naga merah dipasar Gamping Sleman Yogyakarta dan gula pasir merk MK. Beserta reagen proanalitik, untuk uji kimia pada selai. Antara lainaquades, reagen Nelson Somogyi, metanol, DPPH, dan lain-lain diperolehdariprodukMerck danSigma- Aldrich.

Alat-alatyang digunakanuntuk penelitian meliputi nampanplastik,pisau,blender, panci,kompor listrik,gelas 
ukur,timbangan,thermometer,refrigerator, dan

lain-lain.Peralatan gelas dan seperangkat alat penunjang analisis kimia meliputibotol

timbang,desikator,spatula,penjepit,oven, timbangan analit, pipet, vortex, kompor listrik, erlenmeyer, spektrofotometer dan lain-lain.

\section{Metode penelitian}

Metode penelitian dilakukan dengan tiga tahap.

Penelitian pendahuluan untuk menentukan optimalisasi waktu dan penggunaan rasio perbandingan bahanbahan. Dilanjutkan uji kimia pada hasil olahan selai buah naga merah meliputi kadar air, kadar gula total, aktivitas antioksidan (\%RSA) metode DPPH. Dilakukan uji organoleptik untuk ketiga produk olahan dari berbagai waktu pemanasan meliputi uji warna, tekstur dan kesukaan secara keseluruhan (Kartika, dkk., 1988).

U ntukmengetahuipengaruhperlakuant erhadapparameteryang dianalisismaka dilakukanujikeragaman,apabilaterdapatbeda nyatadilakukanujiDuncandengan taraf signifikan 5\%. Analisis / uji organoleptik meliputi warna, tekstur dan kesukaan secara keseluruhan.

\section{Rancangan percobaan}

RAL) yang terdiri dari 5 perlakuan.Tiap perlakuan dilakukan pengulangan sebanyak 3 kali.

\section{HASIL DAN PEMBAHASAN}

Analisis kimia bahan dasar dilakukan untuk mengetahui kondisi bahan mula-mula maupun kandungan gizi.

Tabel 1. Komposisi kimia daun, bunga dan buah kersen segar

Pemanasan/ Kadar Aktivitas Gula

\begin{tabular}{|c|c|c|c|}
\hline Parameter & air (\%) & $\begin{array}{l}\text { antioksidan } \\
(\% \text { RSA })\end{array}$ & $\begin{array}{l}\text { total } \\
(\%)\end{array}$ \\
\hline 35 menit & $35,50 a$ & $60,57 \mathrm{a}$ & $49,32 \mathrm{a}$ \\
\hline 40 menit & $34,29 b$ & $56,58 b$ & $56,60 \mathrm{~b}$ \\
\hline 45 menit & $30,08 \mathrm{c}$ & $54,51 \mathrm{c}$ & $58,37 \mathrm{c}$ \\
\hline 50 menit & $26,73 c$ & $50,56 \mathrm{~d}$ & $60,89 c$ \\
\hline 55 menit & $25,11 d$ & $50,19 d$ & $69,33 \mathrm{e}$ \\
\hline & ngan : & $\begin{array}{l}\text { 1gka yang } \\
\text { sama mena } \\
\text { kuan tidak } \\
\text { taraf signifi }\end{array}$ & $\begin{array}{l}\text { cuti huruf } \\
\text { kan antar } \\
\text { eda nyata } \\
\text { si } 5 \% \text {. }\end{array}$ \\
\hline
\end{tabular}

Berdasarkan hasil analisis diatas menunjukkan bahwa semakin lama pemanasan kadar air selai buah naga merah semakin berkurang. Hal ini disebabkan oleh proses pemanasan menguapakan sebagian kandungan air bebas dalam buah meskipun gula pasir dapat menghambat penguapan namun tidak kuat. Menurut penelitian terdahulu (Laswati, 2018) analisis kadar air pada buah naga merah segar sebesar $87,92 \%$. Menurut (Winarno,1997) air yang terdapat di dalam bahan makanan mempunyai derajad keterikatan yang berbeda-beda.

Pemanasan dapat mengurangi daya tarik menarik antara molekul-molekul air dan memberikan cukup energi kepada molekul-molekul air itu sehingga dapat mengatasi daya tarik menarik antar molekul gula, karena itu daya kelarutan pada bahan yang melibatkan ikatan hidrogen pada gula akan meningkat dengan meningkatnya suhu yang berakibat pada air terikat lebih kuat pada bahan (tidak mudah digunakan oleh mikroorganisme) sehingga produk makanan yang mengandung gula tinggi lewih awet.

Berdasarkan hasil pengujian khususnya aktivitas antioksidan semakin lama pemanasan menunjukkan penurunan yang signifikan. Hal ini diduga karena pemanasan akan mengakibatkan kerusakan pada jaringan buah. Pada penelitian terdahulu (Laswati, 2018) menunjukkan bahwa aktivitas antioksidan buah naga merah segar sebesar 68,91 (\%RSA). Hal ini dikarenakan belum adanya kerusakan masing-masing komponen, antara lain 
kadar air belum terjadi pelayuan begitu pula untuk antosianin dan aktivitas antioksidannya.

Hasil analisis uji organoleptic dapat dilihat pada Tabel 2 berikut ini.

Tabel2. Karakter organoleptik

\begin{tabular}{llll}
\hline $\begin{array}{l}\text { Pemanasan/ } \\
\text { Parameter }\end{array}$ & Warna & Tekstur & Kesukaan \\
& \multicolumn{3}{c}{} \\
\hline 35 menit & $4,51 \mathrm{a}$ & $3,6 \mathrm{a}$ & $3,2 \mathrm{a}$ \\
40 menit & $4,05 \mathrm{~b}$ & $3,9 \mathrm{~b}$ & $4,0 \mathrm{~b}$ \\
45 menit & $3,45 \mathrm{~b}$ & $4,6 \mathrm{c}$ & $4,6 \mathrm{c}$ \\
50 menit & $3,15 \mathrm{c}$ & $4,5 \mathrm{c}$ & $4,25 \mathrm{~d}$ \\
55 menit & $3,05 \mathrm{c}$ & $4,1 \mathrm{~d}$ & $4,2 \mathrm{~d}$ \\
\hline \multicolumn{4}{c}{ Keterangan : Angka yang diikuti huruf yang } \\
\multicolumn{4}{c}{ sama menandakan an antar } \\
& perlakuan tidak berbeda nyata \\
& pada taraf signifikansi $5 \%$.
\end{tabular}

Mutu hasil olahan pangan sangat dipengaruhi oleh mutu bahan dasar/bahan mentah maupun bahan setengah jadi. Sifat mutu suatu benda meliputi sifat yang langsung dapat diamati, secara subyektif serta dianalisis atau diukur secara obyektif.

Secara umum semua selai buah naga merah belum banyak mengalami perubahan warna dibanding denganbuah segar maupun setelah pengolahan. Hal ini karena buah naga merah memiliki pigmen merah keunguan yang sangat pekat. Namun demikian setelah pemanasan pada suhu 90$100^{\circ} \mathrm{Cdengan}$ waktu yang semakin lama tetap terjadi perubahan warna yakni semakin pekat masih seperti warna aslinya. Semakin lama waktu pemanasan menyebabkan warna ungu semakin merah keunguan pekat. Hal ini terkait dengan pigmen betasianin dan antosianin yang terdapat dalam buah naga merah. Antosianin merupakan senyawa antioksidan yang tidak stabil apabila terkena panas. Secara kimia antosianin merupakan turunan struktur aromatik tunggal, yaitu sianidin, dan semuanya terbentuk dari pigmen sianidin dengan penambahan atau pengurangan gugus hidroksil, metilasi dan glikosilasi (Harborne 2005).Antosianin adalah senyawa yang bersifat amfoter, yaitu memiliki kemampuan untuk bereaksi baik dengan asam maupun dengan basa.Dalam media asam antosianin berwarna merah, dan pada media basa berubah menjadi ungu dan biru (Man 1997).Antosianin adalah metabolit sekunder dari famili flavonoid, dalam jumlah besar ditemukan dalam buahbuahan dan sayur-sayuran (Supriyono 2008).Antosianin adalah suatu kelas dari senyawa flavonoid, yang secara luas terbagi dalam polifenol tumbuhan.Flavonol, flavan3-ol, flavon, flavanon, dan flavanonol adalah kelas dari flavonoidyang berbeda dalam oksidasi antosianin.Senyawa flavonoid tidak berwarna atau kuning pucat (Sundari 2008).Antosianin termasuk pigmen larut air yang secara alami, terakumulasi pada sel epidermis buahbuahan, akar, dan daun. Antosianin terdapat pada sejumlah besar buah-buahan seperti : anggur, strawberri, cherri, ubi jalar, serta pada sayuran seperti kol merah dan bayam merah (Hendry 1996; Harborne 1987). Antosianin dapat menggantikan penggunaan pewarna sintetik carmoisin dan amaranth sebagai pewarna merah pada produk pangan. Antosianin dapat digunakan sebagai pewarna alami dalam minuman penyegar, kembang gula, produk susu, roti, kue, jelli, produk awetan, dan sirup (Gross 1991). Hal ini sesuai dengan pernyataan bahwakestabilan antosianin dipengaruhi oleh beberapa faktor antara lain $\mathrm{pH}$, suhu, cahaya, dan oksigen (Basuki dkk, 2005). Menurut Clydesdale (1998) dan Markakis (1982) Pigmen antosinanin (merah, ungu dan biru) merupakan molekul yang tidak stabil jika terjadi perubahan pada suhu, $\mathrm{pH}$, oksigen, cahaya, dan gula. Bahwa gugus hidroksil pada molekul antosianin dapat mempengaruhi kestabilan warna akibat dari penetrasi panas dan waktu. Penurunan kepekatan warna merah keunguan pada buah ubi jalar ungu disebabkan oleh 
terjadinya dekomposisi antosianin dari bentuk aglikon menjadi kalkon (Yudiono, 2011).

Tingkat kelengketan/sifat oles dan kekompakan gel selai buah naga merah yang dipanaskan dengan waktu yang berbeda menyebabkan perbedaan kadar air selai yang dihasilkan. Namun demikian tekstur gel selai buah naga merah masih kenyal dan kompak dalam hal perbedaan teksturnya yakni kompak sampai sangat kompak dan lengket.Waktu pemanasan kurang dari 45 menit selai masih memiliki sifat oles kurang baik (terputusputus/encer). Demikian juga sifat oles selai yang dipanaskan lebih dari 50 menit selai yang dihasilkan sulit dioleskan tekstur terlalu kenyal dan sangat lengket.

Kesukaan merupakan gabungan berbagai persepsi baik antara rasa, warna, aroma maupun tekstur suatu produk makanan, atau dapat dikatakan sebagai respon terhadap kesimpulan dari keseluruhan penilaian panca indera manusia. Pertimbangan-pertimbangan tersebut oleh tiap individu dapat berbeda kesimpulannya karena urutan prioritas tetapi dapat pula sama. hasil uji kesukaan secara keseluruhan panelis memilih sampel ke tiga yakni selai dengan perlakuan lama pemanasan 45 menit. Dengan pertimbangan sifat-sifat yang dimiliki berdasar warna dan tekstur dengan nilai 3,45 warna merah keunguan pekat dan 4,6 sifat oles tekstur kompak dan lengket

\section{KESIMPULAN}

Dari hasil penelitian dan pembahasan dapat disimpulkan bahwa :

Perlakuan lama waktu pemanasan Selai buah naga merah menyebabkan penurunan kadar air dan aktivitas antioksidan (\%RSA) serta peningkatan kadar gula total berturutturut lama waktu 35 menit; 40 menit; 45 menit; 50 menit dan 55 menit adalah Kadar air sebagai berikut 35,5 \%; 34,29\%;
30,08\%; 26,73\% dan 52,11\%; Aktivitas antioksidan (\%RSA) sebagai berikut 60,57; 56,58; 54,51; 50,56; dan 50,19 serta kadar gula total 49,32\%; 56,60\%; 58,37\%; $60,89 \%$ dan $69,33 \%$. Uji organoleptik menyatakan bahwa hasil nilai warna dan tekstur serta kesukaan panelis terhadap Selai buah naga yang dihasilkan disukai) dengan sifat oles tekstur kompak dan lengket, sedangkan warna warna merah keunguan. Oleh karena itu dapat disimpulkan bahwa Selai buah naga merah yang terbaik adalah perlakuan pemanasan suhu $90-100^{\circ} \mathrm{Cselama} 45$ menit, dengan kriteria warna (merah keunguan); tekstur (kenyal kompak dan lengket) dan sangat suka.

\section{DAFTAR PUSTAKA}

Andarwulan, N., H. Wijaya, dan D.T. Cahyono.(1996). Aktivitas Antioksidan dari Daun Sirih (Piper betle L).Teknologi dan Industri Pangan. Hal 29-30.

Astawan M, dan Kasih AL, 2008, Khasiat Warna-warni Makanan, Jakarta, Gramedia Pustaka Umum

Bambang Kartika, Pudji Hastuti dan Wahyu Supartono, 1988. Pedoman Uji Inderawi Bahan Pangan. PAU, Pangan Gizi UGM, Yogyakarta.

Basuki, N., Harijono, Kuswanto, dan Damanhuri.2005. Studi Pewarisan Antosianin pada Ubi Jalar. Agravita27 (1): 63 - 68. ISSN: 0126 $-0537$.

Clydesdale, F.M. 1998. Color : origin, stability, measurement and quality. Didalam Food Storage Stability.Taub, I.A. \& Singh, R. P (Ed) 1998. CRC Press LCC. New York. 
Gross, J. 1991. Pigments In Vegetables (Chlorophylls and Carotenoids). Van Nostrand Reinhold, New York, hal. 1 - 351. Batsford, London

Handayani, Prima Astuti dan Asri Rahmawati. 2012. "Pemanfaatan Kulit Buah Naga (Dragon Fruit) Sebagai Pewarna Alami Makanan Pengganti Pewarna Sintetis. Jurnal Bahan Alam Terbarukan. Vol 1(2): 19-24.

Harborne. 2005. Encyclopedia of Food and Color Additives. CRC Press,Inc. New York.

Hendry. 1996. Natural Food Colours. Di dalam Natural Food Colorants. Hendry, G. A. F. \& J. D. Houghton (ed.). 1996. 2nd ed. Blackie Academic \& Proffesional London.

Hidayah, Tri. 2014. "Uji Stabilitas Pigmen dan Antioksidan Ekstrak Zat Warna Alami KulitBuah Naga”. Indonesian Journal of Chemical Science. 3 (2): 136-140.

Jaafar, Ali., R. Nazri M., Khairuddin, W. 2009. Proxymate Analysis of Dragon Fruit (Hylecereus polyhizus.)American Journal of Applied Sciences. 6:1341-1346

Kumaran, A., and Karunakaran, R.J. 2005. Antioxidants Activities of Methanol Extracts of Five (Phyllanthus urinaria. Jurnal Food and Chemical Toxicology.Vol. 46. Hal. 2485-2492.

Laswati, DT., 2018. Pengaruh waktu pemanasan terhadap sifat kimia dan organoleptik agar-agar buah naga merah (Hylocereus polyrhizus)
Laporan Penelitian Dana DIPA Kopertis Wilayah V Yogyakarta/LLDIKTI. Tahun 2018.

Man, J. M. de. 1997. Kimia Makanan. ITB. Bandung.

Markakis, P. 1982. Anthocyanins as Food Additives.Di dalam Anthocyanins as Food Colors.

Pitojo, S., dan Sumiati. 2005. Cincau: Cara Pembuatan dan Variasi Olahan. Jakarta : Agromedia Pustaka.

Pietta P-G., 1999. Falvonoid as Antioxidants, Review,J. Nat. Prod., 63, 1035-1042.

Prakash A., 2001. Antioxidant Activity, Medaltion Laboratories Analitycal Progres, Vol. 19 (2).

Rivera, J., C. Ordorica, dan P. Wesche. 1998. Changes in Anthocyanin Concentration in Lychee (Litchi chinensis Sonn) Pericarp DuringMaturation. J. Food Chem65 (1999) 195-200.

Slamet Sudarmadji, Bambang Haryono dan Suhardi. 2010. Prosedur Analisa untuk Bahan Makanan dan Pertanian. Liberty. Yogyakarta.

Sundari, U. 2008. Uji Banding Metode Ekstraksi Karotenoid dan Tokoferol Sari Buah Merah.Skripsi. Bogor: Institut Pertanian Bogor.

Supriyono, T. 2008. Kandungan $\beta$-Karoten, Polifenol Total dan Aktivitas "Merantas" Radikal Bebas Kefir Susu Kacang Hijau (Vigna radiata) oleh Pengaruh Jumlah Strater 
(Lactobacillus bulgaricus dan

Candida kefir) dan Konsentrasi

Glukosa.Tesis. Semarang:

Universitas Diponegoro.

Winarno, F.G., 1997. Kimia Pangan dan Gizi. PT. Gramedia Pustaka Utama, Jakarta.

Winarti, Sri. 2008. Ekstraksi Dan Stabilitas Warna Ubi Jalar Ungu (Ipomoea batatas L.,) Sebagai Pewarna Alami. Jurnal Teknik Kimia, Vol.3, No.1:207-214.

Yudiono, K. 2011. Ekstraksi Antosianin dari Ubi Jalar Ungu (Ipomoea Batatas Cv. Ayamurasaki) dengan Teknik Ekstraksi Subcritical Water. Jurnal Teknologi Pangan 2 (1) : 1 -30 